\title{
AGENTES COMUNITÁRIOS DE SAÚDE E OS DESAFIOS DA EDUCAÇÃO PERMANENTE: REFLEXÕES SOBRE A EXPERIÊNCIA DO PROGRAMA TELESSAÚDE BRASIL - NÚCLEO RIO DE JANEIRO
}

\author{
Community Health Agents and the Challenges of Permanent Education: Considerations on the Experience \\ of Brazil's Telehealth Program - Rio de Janeiro Nucleus
}

\section{Carlana Santos Grimaldi Cabral de Andrade'; Helena Maria Shellovick Leal David²}

\begin{abstract}
Resumo Levantamento quanti-qualitativo de perfil socio-demográfico e de uso de internet por Agentes Comunitários de Saúde (ACS) inseridos no Programa Telessaúde Brasil, Núcleo Rio de Janeiro, que se apresenta como programa de real e potencial alcance entre os ACS.
\end{abstract}

Palavras-chave: Profissional de Saúde, Educação Permanente, Educação a Distância, Telessaúde.

\begin{abstract}
Quanti-qualitative study of Community Health Agent's (CHA) sociodemographic and internet use profile inside Brazil Telehealth Program - Rio de Janeiro Center, concluding that it is a program of real and potential extent among the $\mathrm{CHA}$.
\end{abstract}

Keywords: Health Professional, Permanent Education, Distance Education, Telehealth.

Estudo de mestrado que tem como objeto a inserção do Agente Comunitário de Saúde (ACS) no projeto Telessaúde Brasil, Núcleo Rio de Janeiro. Tem-se como pressuposto que a educação permanente constitui-se em instrumento de transformação e qualificação da prática profissional na área da saúde. Objetivo: discutir os usos reais e potenciais das ferramentas de educação a distância pelos ACS do Estado do Rio de Janeiro. Metodologia: combinou-se uma abordagem quantitativa, com análise de dados cadastrais de 100 ACS e registros das teleconferências gravadas do Telessaúde no ano de 2009. A aproximação qualitativa se deu pela análise de narrativas obtidas em oficinas presenciais com 65 ACS. Resultados e discussão: O perfil sócio-demográfico dos ACS da amostra é predominantemente jovem, com idade variando de 23 a 38 anos. Neste grupo, 52\% fazem uso cotidiano da internet, utilizam correio eletrônico, conhecem e acessam bases de dados do Ministério da Saúde (DATASUS e sistema de Informação da Atenção Básica- SIAB). No Núcleo Telessaúde Brasil do Estado do Rio de Janeiro, 555 ACS assistiram a teleconferencias emitidas no ano de 2009. Sobre o trabalho em equipe multidisciplinar, $65 \%$ dos ACS relataram trabalhar em conjunto com médicos, e $68 \%$ com enfermeiros. Apenas $2 \%$ informaram não desenvolver nenhum trabalho em equipe. Quando perguntados sobre seu interesse quanto a futuras capacitações, os temas mais apontados foram saúde da criança (53\%), saúde do idoso (48\%), saúde da mulher (39\%) e doenças crônico-degenerativas (18\%). A abordagem qualitativa trouxe como resultados: os ACS

1. Mestre em Enfermagem - Faculdade de Enfermagem do Estado do Rio de Janeiro; 2. Professora Associada da Faculdade de Enfermagem do Estado do Rio de Janeiro - Professora Doutora em Saúde Pública. 
consideram que oTelessaúde é um espaço para educação permanente e também para troca de experiencias com outros ACS, mas enfrentam dificuldades operacionais para desenvolver e assistir a essas atividades em função das demandas do cotidiano dos serviços, por não possuirem computadores em casa e/ou por dificuldades no acesso a internet em municipios do interior. Conclusóes: o professional ACS mais jovem possui habilidades para acesso a atividades de educação permanente mediadas pela internet, e busca as ferramentas para capacitação e troca de experiencias com outras equipes, apontando para necessidades em termos de capacitação consoantes com as diretrizes da Atenção Básica. O Telessaúde pode ser considerado como um programa de real alcance entre os ACS, com potencial de inovação e atendimento a demandas de educação permanente em saúde. 